\section{US Senate restores proposed cut in science budgets}

Washington

The US Senate has restored cuts proposed by the House of Representatives to next year's budget for the space agency NASA and the National Science Foundation (NSF) (see Nature 401, 103; 1999).

Last week, the Senate appropriations committee passed an appropriations bill for Veterans Affairs, Housing, Urban Development (VA-HUD) and independent agencies that would fund both agencies at the levels proposed by President Bill Clinton in February. At these levels, the NSF's budget would increase by $\$ 250$ million to $\$ 3.9$ billion, and NASA's would be held at $\$ 13.6$ billion.

The committee's action, which was expected to be endorsed by the full Senate this week, increases the probability that the two agencies will be funded at these levels. The Senate and House proposals will be reconciled later this month, before a joint VA-HUD bill is sent to Clinton for his signature. His advisers have said that he would veto the House's proposed \$1 billion cut at NASA.

NSF director Rita Colwell, whose initiatives in biocomplexity and supercomputer research were threatened by the cuts, says: "We aren't at the finish line yet, but I am breathing more easily".

The Senate obtained extra money for its VA-HUD bill by transferring several billion dollars from the bill for labour, health and education. Both houses of Congress have been tapping the labour bill's allocation all summer, so that it is some $\mathbf{2 0}$ billion short of the $\$ \mathbf{9 0}$ billion its programmes are expected to cost.

According to government officials, Senate appropriators believed the labour bill's allocation was already so low that it had no chance of passing. "Taking another few billion dollars from it won't make any difference," explains one official. The programmes in the labour bill, which include some for the National Institutes of Health, are almost certain to receive temporary funding.

There are various schemes afoot to rescue the labour bill. Most involve using money due to be spent after 1 October 2000, when the financial year ends, so that Congress can claim it did not break its spending cap.

Another option would be for either Congress or Clinton to admit that they cannot operate under the spending caps set by the Budget Balancing Act of 1997, which assumed cuts that Washington has been unable to implement. Colin Macilwain

\title{
Survey finds deep insularity among Japanese scientists
}

\section{Tokyo}

Japanese researchers should place greater emphasis on the quality of their scientific papers rather than their quantity, and make more effort to publish in international journals and to communicate with foreign researchers. These are the conclusions of a survey released last week by the Science and Technology Agency (STA).

Although 63.5 per cent of the 416 researchers surveyed said that they prefer to submit papers to journals with high impact factors, 26.2 per cent do not consider impact factors as important. This reflects the fact that some institutes - particularly national laboratories and universities - still consider the total output of papers as the main criterion for assessing research activities.

The report also shows that only about 40 per cent of Japanese researchers communicate with foreign researchers using electronic mail or faxes - and a similar proportion appear not to communicate with foreign researchers at all.

The report is based on a survey of researchers at universities and private and government institutes in Japan who produced scientific papers between March 1998 and March 1999. Those who participated in the survey produced an average of two papers during this period, with university researchers tending to produce more papers than those at private institutes, according to the report.

Japan produced more than 10 per cent of the total output of scientific papers in the 1997 index of the Institute for Scientific Information, ranking second after the United States. But a separate analysis based on average citations per paper placed Japan seventeenth, and below the world average.

The STA report raises concern over the number of Japanese researchers who do not publish in international journals, and says that more active participation in international publishing should be encouraged.

The survey revealed that about 40 per cent of the researchers only submit papers to Japanese publications, while 34.1 per cent also submit to international journals.

The survey also shows that only 20 per cent communicate regularly with overseas researchers. Of these, 39 per cent use e-mail, faxes and letters, while 24 per cent say they only communicate in person, and only 0.2 per cent do so by telephone.

"Considering the advances in information technology, I am surprised that more researchers do not use e-mail," says one STA official. "I cannot believe that some still depend on direct person-to-person contact as a means of communicating with overseas researchers."

The report says that Japanese researchers tend to be poor at communicating with overseas researchers. This is one reason for their relative lack of involvement in international science.

Asako Saegusa

\section{Celebratory pictures from Subaru}

\section{Tokyo}

The latest images from Subaru, one of the world's largest optical telescopes, were unveiled last week by Japan's National Astronomical Observatory to celebrate the completion of the 8.3-metre telescope.

Vivid images of the Ring Nebula (M57), the radio galaxy B3 0731438 and Subaru deep field, a wide field near the North Galactic Pole, were released during the ceremony, which took place on Mount Mauna Kea in Hawaii, where the telescope is located.

Subaru gathered its first light in February (see Nature 397, 380; 1999), but last week's images are some of the first to be released since its full operation began in April this year. The images of the Ring Nebula (see right) show the details of its outer halo, revealing its two components: a bright inner part with many loops, and a fainter, more detached, outer part.

These observations contribute to the

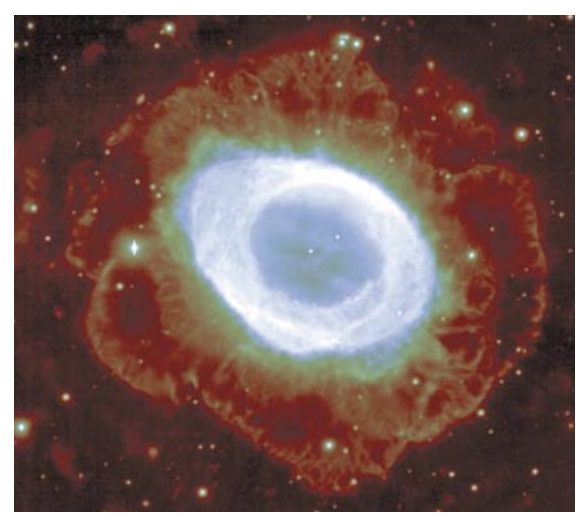

Gas rings: the Subaru telescope has captured the inner and outer haloes of the Ring Nebula.

study of how the planetary nebula emerged. Subaru has also captured images of the active galactic nucleus in a radio galaxy 9.2 billion light years from the Earth.

A.S. 